Case Report

\title{
A rare complication of brucella in adolescence: Epididymoorchitis
}

\author{
Mehmet semih DEMIRTAŞ ${ }^{1}$ \\ ${ }^{1}$ Aksaray University Training and Research Hospital Deparment of Pedatrics, Aksaray, Turkey
}

\begin{abstract}
Summary: Brucellosis is a systemic infectious disease and one of the major public health problems in our country. Genitourinary system involvement is rarely seen in brucellosis, which can involve many organs and systems. A 15-year-old patient who presented with scrotal swelling and pain and subsequently diagnosed as brucella epididymoorchitis is described in this case report. Since brucella rarely presents with epididymoorchitis, it is necessary to keep in mind the differential diagnosis of scrotal diseases, especially in areas where the disease is endemic. Diagnosis can be made with a good anamnesis and laboratory tests and the disease can be controlled with appropriate treatment.
\end{abstract}

Key Words: Brucellosis, child, epididymoorchitis

\section{Introduction}

Brucella is a zoonotic disease that can involve many organs and tissues. Brucellosis that seen in the Balkans, Middle East, South America and Mediterranean region where Turkey is located, is also an important public health problem (1-3). According to the data of the Ministry of Health, 18408 cases of brucellosis were reported in our country in 2004 and the cases are mostly seen in rural areas of Central and Southeastern Anatolia (4). The disease is transmitted to humans by direct contact with infected animals or by consumption of unpasteurized milk and milk products of infected animals $(5,6)$. Brucellosis is seen in a wide spectrum of symptoms ranging from fever, joint pain and weakness to cardiovascular, genitourinary and nervous system involvement $(2,7,8)$. Lymphohematogenous spread can involve many systems such as osteoarticular system, central nervous system and hematologic system (9). Epididymoorchitis, a rare complication, has been reported in $2 \%$ to $20 \%$ of cases (6-8). Epididymoorchitis has been seen in $3.4 \%$ of the cases with brucellosis in studies conducted in our country (4). This complication of brucellosis is mostly seen in the young adult age group. This complication was not defined in large series in childhood $(9,10)$.

In our case report, we present a pediatric case who presented with the complaints of scrotal pain and swelling except for the usual symptoms and diagnosed as brucella epididymoorchitis.

\section{Case Report}

A 15-year-old male patient was admitted to the pediatric emergency department with complaints of swelling, redness, and pain at the scrotum, which had started 5 days ago. The patient was consulted to the urology department from the emergency department and referred to the pediatric outpatient clinic for treatment. On physical examination, he weight was $57 \mathrm{~kg}(25-50 \mathrm{p})$ and height was $175 \mathrm{~cm}(50-75 \mathrm{p})$, and his vital signs were stable. There was swelling, tenderness and temperature increase in the right scrotum. (Figure 1). Other system examinations were normal. In the anamnesis, it was learned that his complaints started one week after the feast of sacrifice, that he was in contact with animals during this period and that there was no consumption of raw milk and cheese. In laboratory examinations, the number of leukocytes was 15,000 / mm3 (formula leukocytes; polymorphonuclear cells $62 \%$, lymphocytes $33 \%$, monocytes $5 \%$ ), erythrocyte sedimentation rate $38 \mathrm{~mm} / \mathrm{h}$, C-reactive protein level (crp) $13.2 \mathrm{mg} / \mathrm{L}$ (normal values: 0.0 -5.0). Blood biochemical parameters and complete urinalysis were normal. In the tests performed for brucellosis, Rose Bengal test was positive and Wright agglutination test was 1/1280 titer positive. On scrotal ultrasonography (USG), both testes were normal size, right testicular parenchyma was heterogeneous and right epididymal size and vascularization increased. The left testis and epididymis are natural in size and parenchymal echo. This appearance was consistent with epididymo-orchitis. The patient was hospitalized with the diagnosis of brucella epididymo-orchitis. The patient was started on doxycycline and rifampicin treatments and cold application and elevation was applied to the scrotum. Ampicillin was added to the treatment with the recommendation of the pediatric surgery department. On the 7th day of the treatment, the patient had no significant pain and swelling in his testis and his CRP level decreased to $3 \mathrm{mg} / \mathrm{L}$. He was discharged with the suggestion that rifampicin and doxycycline treatment should be completed for 6 weeks and that he would apply to the pediatric infection polyclinic after discharge. 


\section{Mehmet semih DEMIRTAŞ et. al/ A rare complication of brucella in adolescence: Epididymoorchitis}

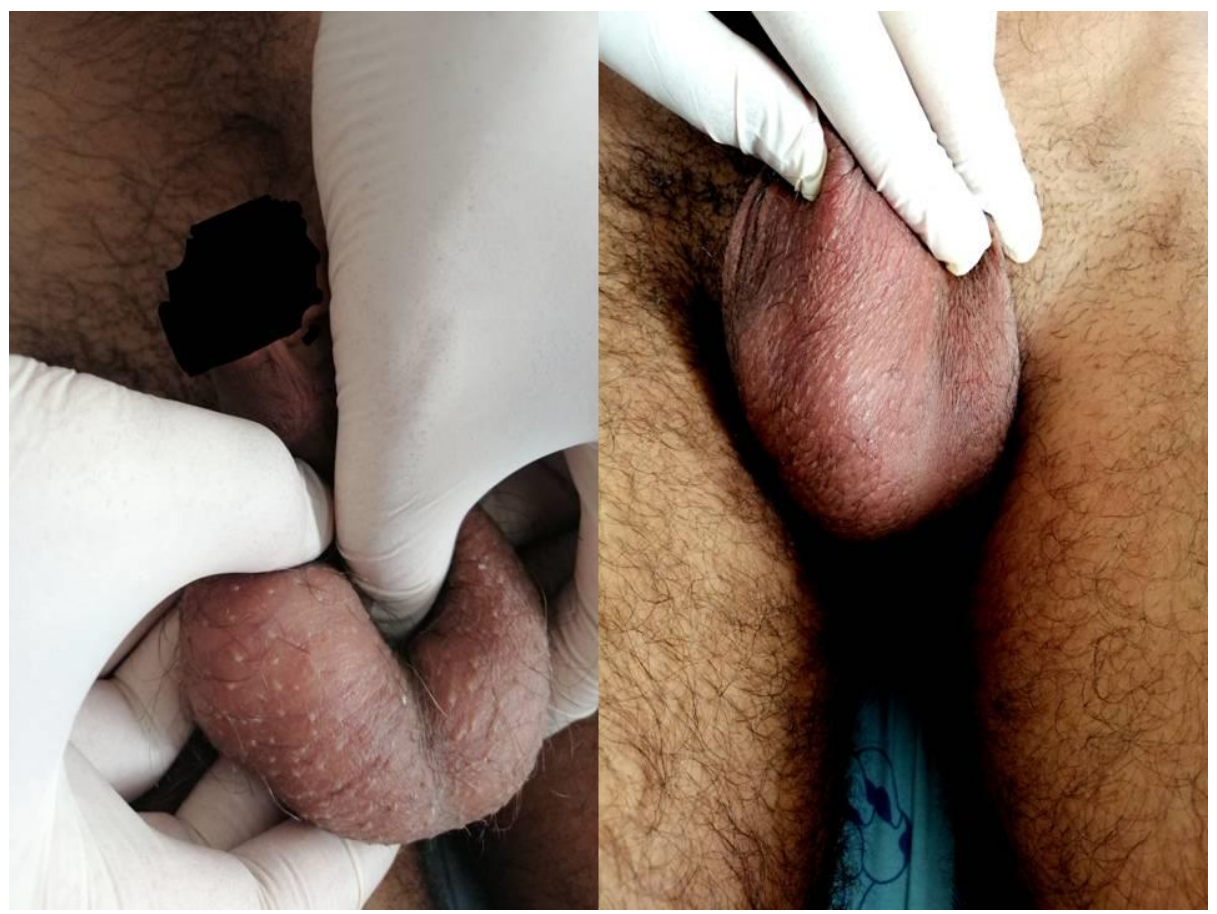

Figure 1. Increase in right testis size and redness are shown

\section{Discussion}

Brucellosis is a zoonotic disease caused by bacteria of the genus Brucella, which can involve many organs and systems. Brucellosis may present with a wide range of non-specific symptoms and clinical findings that are easily confused with many other diseases (11). Genitourinary system involvement may develop in 2-20\% of patients with brucella infection; clinically, prostatitis, epididymo-orchitis, cystitis, pyelonephritis, exudative glomerulonephritis and renal abscesses may occur (12).

Epididymo-orchitis is the most common genitourinary complication of brucellosis, first described by Hardy in 1928 and Wainwright in 1929 as a cause of granulomatous orchitis (13). Epididymo-orchitis may be seen as a symptom of relapses during the course of systemic disease or in poorly treated cases or as a separate clinical picture without systemic disease symptoms $(6,14)$. Testicular involvement in brucella epididymoorchitis is usually unilateral as in our case. Isolated testicular involvement is rare, often accompanied by epididymitis $(7,15)$. The most common symptoms are scrotal pain and swelling, which may be accompanied by fever. Microscopic examination of urine is normal in cases with testicular involvement, and no growth is detected in culture.

History of contact with animals, consumption of unpasteurized dairy product, typical coronary fever and abnormal urologic findings support the diagnosis. In the standard tube agglutination test, $\geq 1 / 160$ titer was detected and the growth of brucellosis in blood culture was important. Brucella can also be produced in ejaculate cultures in cases with epididymoorchitis (14). Ultrasonography plays an important role in the diagnosis of epididymoorchitis. Diffuse hypoechoic testis or focal intratesticular areas can be detected in the enlarged and heterogeneous epididymis and testicular involvement on ultrasonography (15). In addition, thickening of the scrotal wall and tunica albugine and moderate hydrocele are also observed (16,17). In our case, brucellosis was considered with the findings that started 1 week after the feast of the sacrifice and a history of contact with animals during the feast and the diagnosis was made by tube agglutination and Rose Bengal test. In addition, ultrasound findings supported epididymoorchitis.

Sperm analysis can be detected in almost every patient in the acute infection period in brucella epididymoorchitis.Oligospermia and azospermia may persist in very few cases after treatment. Prolonged infections can cause irreversible damage such as aspermia, infertility, testicular loss, necrotizing orchitis, and it will be appropriate to follow up the patient with sperm analysis (18).

Standard brucella treatment according to age is sufficient for children and adolescents who had treatment of Brucella epididymoorchitis. Long-term combined antibiotic therapy prevents relapses. The combined treatment of doxycycline-rifampicin or doxycycline-streptomycin for six to eight weeks is the first choice in epididymoorchitis $(2,19)$. Surgical drainage and rarely orchiectomy may be required in patients with testicular abscess (20).

As a result, brucella may rarely present with epididymoorchitis condition. In the differential diagnosis of scrotal diseases, it is important to keep in mind that the epididymoorchitis due to brucella especially in the endemic areas. Diagnosis can be made with a good anamnesis and laboratory tests. Complications such as necrotizing orchitis, oligospermia and azospermia can be prevented with an adequate and appropriate treatment method. 


\section{References}

1. Schutze GE, Jacobs RF. Brucella. In: Kliegman RM, Stanton BF (eds). Nelson Textbook of Pediatrics. 19th ed. Elsevier Saunders; 2012, p. 980-2.

2. Bukhari EE. Pediatric brucellosis. An update review for the new millennium. Saudi Med J. 2018 Apr;39(4):336-341. doi: 10.15537/smj.2018.4.21896. Review.

3. Bosilkovski M, Krteva L, Caparoska S, Labacevski N, Petrovski M. Childhood brucellosis: Review of 317 cases. Asian Pac J Trop Med. 2015 Dec;8(12):1027-1032. doi: 10.1016/j.apjtm.2015.11.009.

4. Buzgan T, Karahocagil MK, Irmak H, Baran AI, Karsen H, Evirgen O, Akdeniz H. Clinical manifestations and complications in 1028 cases of brucellosis: a retrotpective evaluation and review of literature. Int J Infect Dis 2010; 14: 469-78.

5. Serpa JA, Knights S, Farmakiotis D, Campbell J. Brucellosis in Adults and Children: A 10-Year Case Series at Two Large Academic Hospitals in Houston, Texas. South Med J. 2018 Jun;111(6):324-327. doi: 10.14423/SMJ.0000000000000810.

6. Çıraklı S, Karlı A, Şensoy G, Belet N, Yanık K, Çıraklı A. Evaluation of childhood brucellosis in the central Black Sea region. Turk J Pediatr. 2015 Mar-Apr;57(2):123-8.

7. Celen MK, Ulug M, Ayaz C, Geyik MF, Hosoglu S. Brucellar epididymo-orchitis in southeastern part of Turkey: an 8 year experience. Braz J infect Dis 2010; 14: 109-15.

8. Kasap T, Küpeli S. Brucella abortus Causing Febrile Neutropenia Together with Epididymoorchitis. Indian J Pediatr. 2016 Sep;83(9):1022-3. doi: 10.1007/s12098-016-2125-z.

9. Bréhin C, Ray S, Honorat R, Prère MF, Bicart-See A, Claudet I, Grouteau E. (Pediatric brucellosis : A case report and literature review). Arch Pediatr. 2016 Jul;23(7):719-22. doi: 10.1016/j.arcped.2016.04.012.

10. Parlak M, Akbayram S, Doğan M, Tuncer O, Bayram Y, Ceylan N et al. Clinical manifestations and laboratory findings of 496 children with brucellosis in Van, Turkey. Pediatr Int. 2015 Aug;57(4):586-9. doi: 10.1111/ped.12598

11. Christenson JC. Brucellosis. In: Jenson HB, Baltimore RS (eds). Pediatric Infectious Diseases. (2nd ed), Philadelphia: WB Saunders Company, 2002: 379-82.

12. Karaman K, Akbayram S, Bayhan GI, Dogan M, Parlak M, Akbayram HT, et al. Hematologic Findings in Children With Brucellosis: Experiences of 622 Patients in Eastern Turkey. J Pediatr Hematol Oncol. 2016 Aug;38(6):463-6. doi: 10.1097/MPH.0000000000000612.

13. Sasan MS, Nateghi M, Bonyadi B, Aelami MH. Clinical features and long term prognosis of childhood brucellosis in northeast iran. Iran J Pediatr. 2012 Sep;22(3):319-25.

14. Yoldas T, Tezer H, Ozkaya-Parlakay A, Sayli TR. Clinical and laboratory findings of 97 pediatric brucellosis patients in central Turkey. J Microbiol Immunol Infect. 2015 Aug;48(4):446-9. doi: 10.1016/j.jmii.2014.04.016.

15. Baykan AH, Sayiner HS, Inan I.Brucella and non-Brucella epididymo-orchitis: comparison of ultrasound findings. Med Ultrason. 2019 Aug 31;21(3):246-250. doi: 10.11152/mu-1871.

16. Najafi N, Ghassemian R, Davoody AR, Tayebi A. An unusual complication of common endemic disease: clinical and laboratory aspect of patients with brucella epididymoorchitis in the North of Iran. BMC Res Notes 2011; 4: 286.

17. Van Winkle-Preston L, Drew ML. Pediatric brucellosis: a case study. J Pediatr Health Care. 2014 Mar-Apr;28(2):17781. doi: 10.1016/j.pedhc.2013.07.013.

18. Akıncı E, Bodur H, Cevik MA, Erbay A, Eren SS, Ziraman I et al. A complication of brucellosis: Epididymoorchitis. Int J Infect Dis 2006; 10: 171-7.

19. Megged O, Chazan B, Ganem A, Ayoub A, Yanovskay A, Sakran W, et al. Brucellosis Outbreak in Children and Adults in Two Areas in Israel. Am J Trop Med Hyg. 2016 Jul 6;95(1):31-4. doi: 10.4269/ajtmh.16-0116.

20. Wang X, Yan Y, Wu F, Su G, Li S, Yuan X et al. Sixteen Chinese pediatric brucellosis patients onset of fever in nonepidemic areas and 8 developed with osteoarticular involvement. Clin Rheumatol. 2018 Jan;37(1):145-149. doi: $10.1007 / \mathrm{s} 10067-017-3819-\mathrm{y}$. 